\title{
Serum Myoglobin in Acute Cerebrovascular Diseases
}

\author{
YOSHIHIRO SATO, KATSUHIRO MIZOGUCHI, YOUSUKE SATO, \\ TAKASHI HAYASHI*, KAZUHITO SHOJIMA*, YUJI OKAMOTO*, \\ AND MASARO KAJI** \\ Departments of Neurology and Neurosurgery*, St. Mary's Hospital and **Department \\ of Internal Medicine, Kurume University School of Medicine, Kurume, 830 Japan
}

Received for publication June 20, 1985

\begin{abstract}
Summary: Concentration of myoglobin in serum was measured from 114 patients with acute cerebrovascular diseases and compared with serum creatine phosphokinase (CPK) and aldolase activities. The results obtained were as follows: (1) Elevated activity of myoglobin was observed in various types of stroke as well as CPK and aldolase. (2) The myoglobin level was significantly higher in patients with thalamic hemorrhage than in those with cortical infarction, while no difference was observed in other types of stroke. (3) The level of myoglobin was correlated well with the CPK level, but not with aldolase. (4) Correlation between myoglobin and level of consciousness was not observed. (5) No difference in myoglobin concentration in patients was observed between the died within four weeks and the survived. These results indicated that measurement of serum myoglobin in acute cerebrovascular diseases would not be useful for determining the type, severity and prognosis of the diseases.
\end{abstract}

Key words : myoglobin - creatine phosphokinase - aldolase - cerebrovas cular disease - skeletal muscle

\section{Introduction}

There have been some reports indicating that increases in muscle enzymes such as creatine phosphokinase (CPK), aldolase and lactic dehydrogenase activities in serum occur in patients with acute cerebrovascular diseases (Acheson et al. 1965; Dubo et al. 1967; Shiavone and Kaldor, 1965; Ueda et al. 1977; Wolintz et al. 1969). Although recent reports indicated that serum myoglobin was a sensitive indicator of striate muscle cell damage (Miyoshi et al. 1978), it has not been studied in acute cerebrovascular diseases. The present study was undertaken in order to investigate correlation of myoglobin with CPK and aldolase levels in acute cerebrovascular diseases. We discussed the relation of myo- globin with these for clinical implication and prognosis of the patients.

\section{Material and Method}

114 patients (66 men, 48 women, mean age 63.0 years) admitted to the St. Mary's Hospital of Kurume with stroke of less than 24 hours after onset were studied. Patients who had convulsive seizure, acute myocardial infarction or renal dysfunction were excluded. The diagnosis was based on clinical and CT findings (Table 1). Cerebral angiography was also performed on patients with subarachnoid hemorrhage.

Immediately after admission, blood was withdrawn from each patient and stored at -20 degrees centigrade in different tubes 
for later determination of myoglobin, CPK and aldolase. Myoglobin was determined by commercially available radioimmunoassay with ${ }^{125}$ I-labeled and unlabeled myoglobin preparations. CPK and aldolase were assayed by kinetic method. Reference values for men and women were as follows (mean \pm 2 S. D. ) : myoglobin $37.5 \pm 22.5 \mathrm{ng}$ $/ \mathrm{ml}, 22.5 \pm 12.5 \mathrm{ng} / \mathrm{ml}$, CPK $56 \pm 29 \mathrm{IU}, 46$ $\pm 22 \mathrm{IU}$, respectively, and aldolase $1.8 \pm 1.3$ $\mathrm{mU} / \mathrm{ml}$ for both.

\section{Results}

As shown in Table 2, elevation of myoglobin was seen in $67(58.8 \%)$ out of 114 , all types of stroke patients except for subcortical and cerebellar hemorrhage. CPK was high in 37 out of $110(33.6 \%)$ and aldolase in 20 out of 114 patients (17.5\%).

The myoglobin level was considerably higher in patients with thalamic hemorrhage than in those with cerebral infarction of cortical artery $(0.02<\mathrm{P}<0.05)$, while no difference was observed in other types of stroke (Fig. 1).

The levels of myoglobin were significantly correlated with the CPK activities $(\mathrm{r}=0.7208, \mathrm{P}<0.01$, Fig. 2), but not with aldolase $(r=0.2184$, Fig. 3$)$.

Correlation between myoglobin and degree of consciousness of patients was not observed ( $\mathrm{r}=0.0779$, Fig. 4).

There was no difference in myoglobin concentration in patients, who died within four weeks, from patients who survived (Fig. 5).

TABLE 1

Diagnosis of 114 patients

\begin{tabular}{cc} 
Type of Stroke & No. of Patients \\
\hline Hemorrhages & 77 \\
subarachnoid & 27 \\
putaminal & 24 \\
thalamic & 20 \\
pontine & 4 \\
subcortical & 1 \\
cerebellar & 1 \\
Infarctions & 37 \\
cortical artery & 23 \\
perforating artery & \\
Total & 14 \\
\hline
\end{tabular}

Infarction of cortical and perforating arteries is diagnosed by the criteria of Murai et al. (1981).

TABLE 2

Elevations of serum myoglobin, CPK and aldolase levels in subgroups of stroke patients

\begin{tabular}{|c|c|c|c|c|c|c|}
\hline \multirow[b]{2}{*}{ Type of Stroke } & \multicolumn{2}{|c|}{ Myoglobin } & \multicolumn{2}{|c|}{ CPK } & \multicolumn{2}{|c|}{ Aldolase } \\
\hline & $\begin{array}{l}\text { Number } \\
\text { of cases }\end{array}$ & $\begin{array}{l}\text { Number of } \\
\text { elevation }\end{array}$ & $\begin{array}{l}\text { Number } \\
\text { of cases }\end{array}$ & $\begin{array}{c}\text { Number of } \\
\text { elevation }\end{array}$ & $\begin{array}{l}\text { Number } \\
\text { of cases }\end{array}$ & $\begin{array}{l}\text { Number of } \\
\text { elevation }\end{array}$ \\
\hline \multicolumn{7}{|l|}{ Hemorrhages } \\
\hline subarachnoid & 27 & $20(74.1 \%)$ & 26 & $10(38.5 \%)$ & 27 & $1(3.7 \%)$ \\
\hline putaminal & 24 & $13(54.2 \%)$ & 23 & $7(30.4 \%)$ & 24 & $7(29.2 \%)$ \\
\hline thalamic & 20 & $12(60.0 \%)$ & 20 & $10(50.0 \%)$ & 20 & $4(20.0 \%)$ \\
\hline pontine & 4 & $2(50.0 \%)$ & 4 & $1(25.0 \%)$ & 4 & $2(50.0 \%)$ \\
\hline other type & 2 & $0(0 \%)$ & 2 & $0(0 \%)$ & 2 & $0(0 \%)$ \\
\hline \multicolumn{7}{|l|}{ Infarctions } \\
\hline cortical artery & 23 & $12(52.2 \%)$ & 22 & $4(18.2 \%)$ & 23 & $5(21.7 \%)$ \\
\hline perforating artery & 14 & $8(57.1 \%)$ & 13 & $5(38.5 \%)$ & 14 & $1(7.1 \%)$ \\
\hline Total & 114 & $67(58.8 \%)$ & 110 & $37(33.6 \%)$ & 114 & $20(17.5 \%)$ \\
\hline
\end{tabular}




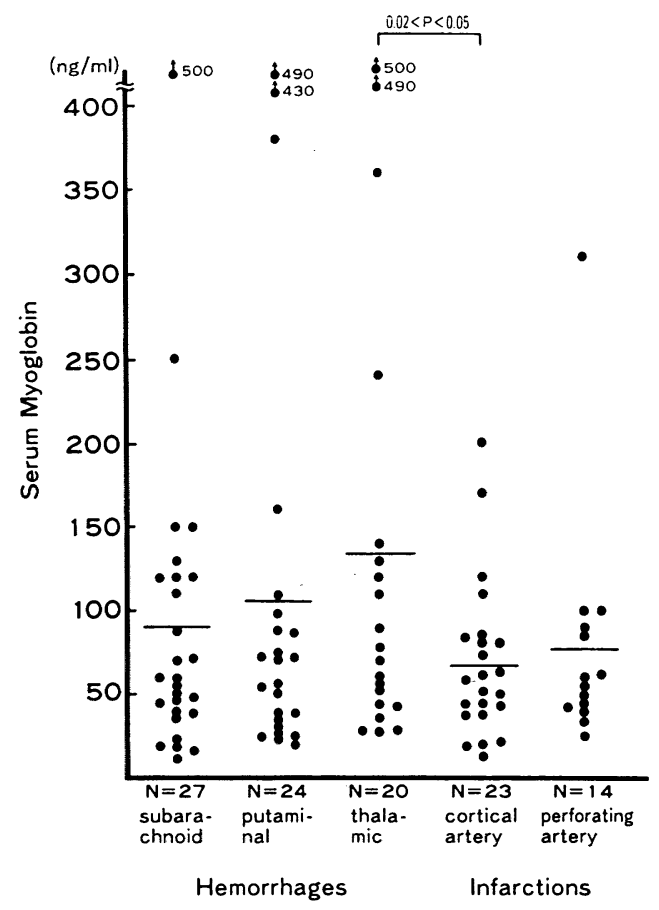

Fig. 1. The serum myoglobin level in subgroups of stroke patients. The line indicates the median score in each group.

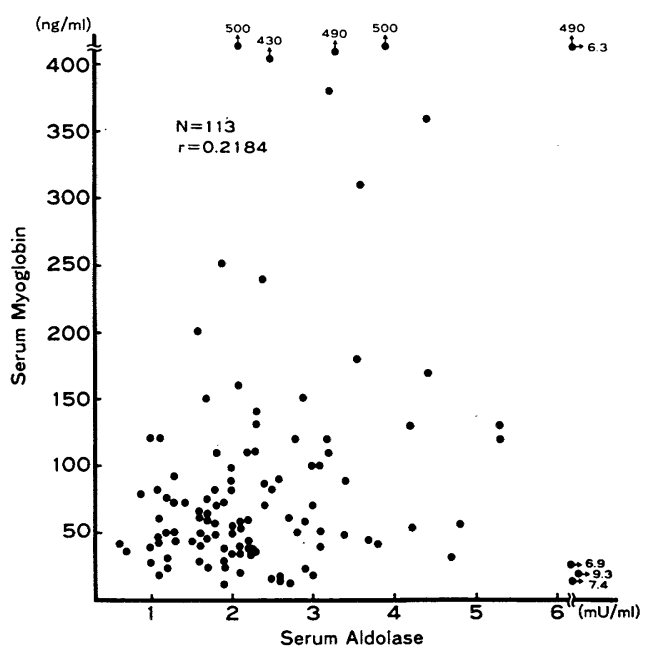

Fig. 3. Correlation between serum myoglobin and aldolase levels.

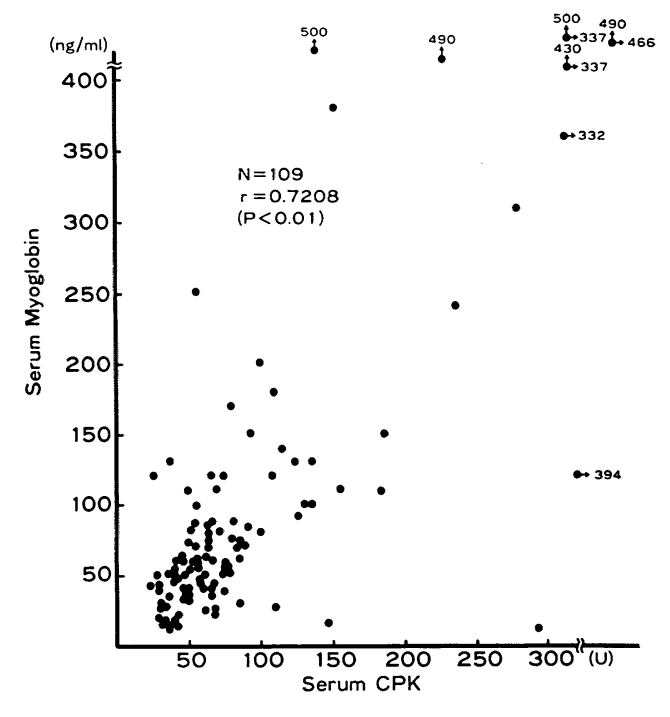

Fig. 2. Correlation between serum myoglobin and CPK levels.

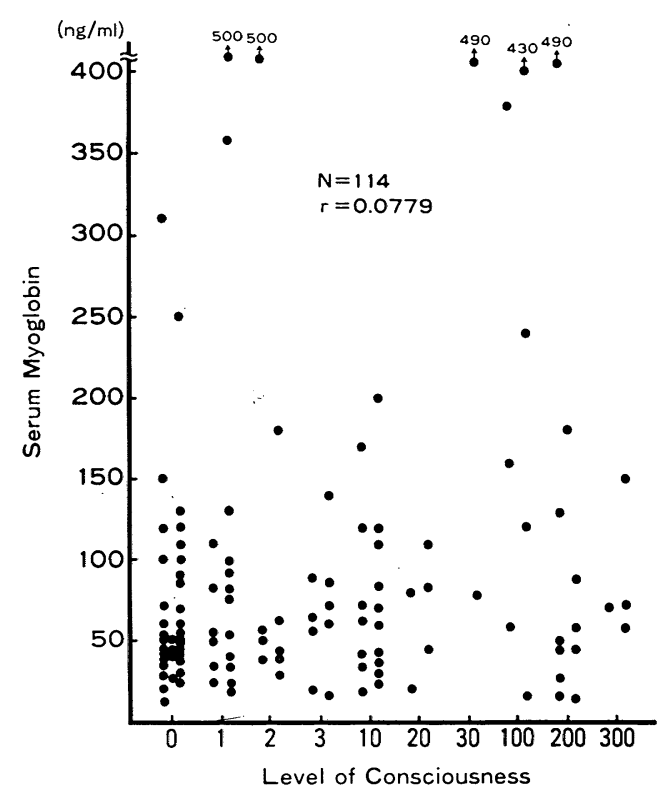

Fig. 4. Relationship between serum myoglobin level and levl of consciousness. Degree of consciousness is judged by 3-3-9 formula (Ohta et al. 1974). 


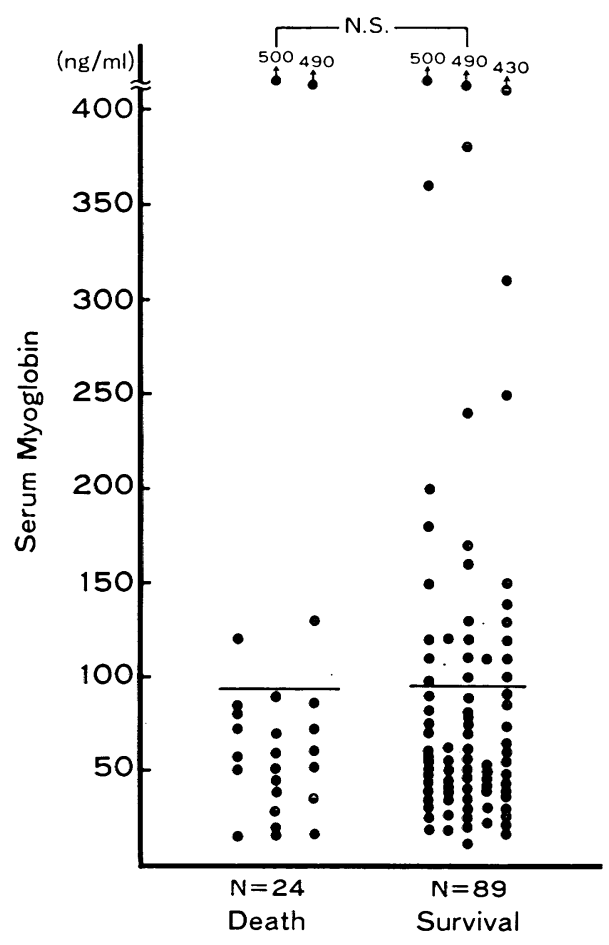

Fig. 5. Serum myoglobin level in dead and survival cases. The line indicates the median score in each group. N.S.: not significant.

\section{Discussion}

Myoglobin is a single-chain polypeptide which has a single heme group and iron content of $0.34 \%$ with a molecular weight of 17,450 to 17,920 (Perkoff et al. 1962). It exists in cytoplasm of muscle cell and has a function to carry oxygen from blood to muscular tissue. Its elevation in serum has been described in progressive muscular dystrophy, polymyositis, renal failure, hypothyroidism and acute myocardial infarction (Haellgren et al. 1978; Kiessling and Beckmann, 1981; Miyoshi et al. 1978; Shimoda and Kasai, 1980; Varki et al. 1978).

It has been reported that elevations of
CPK, aldolase and lactic dehydrogenase were derived from skeletal muscular cell rather than brain in acute cerebrovascular diseases (Dubo et al. 1967; Ueda et al. 1977). However, serum myoglobin has not been studied in acute cerebrovascular diseases. We found that serum myoglobin were increased in $58.8 \%$ cases during the acute phase of cerebrovascular diseases. Measurement of serum myoglobin was not useful at all to determine the type of stroke, as no difference was observed ineach types of stroke except for between thalamic hemorrhage and cortical infarction. Despite myoglobin had poor relation with aldolase activity, it correlated well with CPK. So that both myoglobin and CPK might have a same origin, that is, skeletal muscle.

For the elevation of serum myoglobin in acute phase of cerebrovascular diseases, we postulate a mechanism in which permeability of muscle cell membrane increases rather than destruction of the cells. The increased permeability was thought to be due to disorder of autonomic innervation to intramuscular vessel, muscular hypoxia or decreased in blood supply to muscle (Loegering and Critz, 1971; Ueda et al. 1977).

In the present study, there was little correlation between the myoglobin rise and clinical prognosis. Some patients who had normal myoglobin value died in acute stage but some patients who had markedly elevated myoglobin survived. Furthermore, a poor correlation was observed between elevation of myoglobin and level of consciousness.

Although measurement of serum myoglobin in acute cerebrovascular diseases would not be useful for determining the type, severity and prognosis, the fact of the elevation of serum myoglobin in these diseases should be understood for clinical practice. 


\section{References}

Acheson, J., James, D. J., Hutchinson, E.C. and Westhead, R. (1965). Serum-creatine-kinase levels in cerebral vascular disease. Lancet, 1, 1306-1307.

Dubo, H., Pennington, R. J.T., Kalbag, R.M. and Walton, J.N. (1967). Serum-creatine-kinase in cases of stroke, head injury, and meningitis. Lancet, 2, 743-748.

Haellgren, R., Karlsson, F. A., Roxin, L.E. and VENGE, P. (1978). Myoglobin turnover-influence of renal and extrarenal factors. J. Lab. Cli. Med. 91, 246-254.

Kiessling, W. R. and Beckmann, R. (1981). Serum levels of myoglobin and creatine kinase in Duchenne muscular dystrophy. Klin. Wochensch. 59, 347-348.

Loegering, D. J. and Critz, J.B. (1971). Effects of hypoxia and muscular activity on plasma enzyme levels in dogs. Am. J. Physiol. 220, 100-104.

Miyoshi, K., Saito, S., Kawai, H., Kondo, A., Iwasa, M., Hayashi, T. and Yagita, M. (1978). Radioimmunoassay for human myoglobin; methods and results in patients with skeletal or myocardial disorders. J. Lab. Clin. Med. 92, 341-352.

Murai, A., Tanaka, T., Miyahara, T. and KameYAMA, M. (1981). Lipoprotein abnormalities in the pathogenesis of cerebral infarction and transient ischemic attack. Stroke, 12, 167172.

Ohta, T., Waga, S., Handa, H., Saito, I., Takeuchi, K., Suzuki, J. and Takaku, A. (1974). New grading of level of consciousness. Neurol. Surg. (Tokyo) 2, 623-627.

Perkoff, G.T., Hill, R.L., Brown, D.M. and TYLER, F.H. (1962). The characterization of adult human myoglobin. J. Biol. Chem. 237, 2820-2827.

Schiavone, D. J. and Kaldor, J. (1965). Creatine phosphokinase levels and cerebral disease. Med. J. Aust. 2, 790-792.

Shimoda, S. and KASAI, K. (1980). A clinical evaluation of the increased serum myoglobin, creatine phosphokinase and lactic dehydrogenase in patients with thyroid disorders. Folia Endocrinol. Jap. 56, 1096-1106.

Ueda, K., Ohhara, T., Hatanaka, Y., Nishikawa, M. and Shiotani, Y. (1977). Electrical stimulation on male rabbit hypothalamus and serum enzymes. Clin. Neurol. (Tokyo) 17, 506-512.

VARKi, A.P., Roby, D. S., Watts, H. and Zatuchi, J. (1978). Serum myoglobin in acute myocardial infarction; a clinical study and review of the literature. Am. Heart J. 96, 680-688.

Wolintz, A. H., Jacobs, L. D., Christoff, N., Solomon, M. and CherNiK, N. (1969). Serum and cerebrospinal fluid enzymes in cerebrovascular disease. Arch. Neurol. 20, 54-61. 